\title{
El naixement de la sèquia Major de Corbera a començaments del segle XVI
}

\author{
Salvador Vercher Lletí \\ Arxiu Municipal d'Alzira \\ salvador_vercher@yahoo.es
}

\begin{abstract}
Resumen. En 1516 comienza a construirse la acequia Major de Corbera. El nacimiento de este sistema de riego, de origen fluvial, no es un hecho aislado, sino que se enmarca dentro de la "revolución hidraulica" que transformó la comarca durante los siglos XV y XVI. El promotor del nuevo canal de irrigación será el señor de la baronía de Corbera, Joan de Borja y Enríquez, duque de Gandia, quien posibilitará que Miquel de Maganya construya el bocacaz de la acequia y que Pedro Donzell construya esta, no sin antes haber vencido la oposición del consejo municipal de Sueca.
\end{abstract}

Palabras clave. Acequia, ingenieros hidráulicos, baronía de Corbera, Joan de Borja i Enríquez.

\begin{abstract}
In 1516 began the construction of the Corbera's Major canal. The origin of this irrigation fluvial system is located in the "the hydraulic revolution" which transformed the region during the 15th and 16th centuries. The promoter of the new irrigation canal was the lord of Corbera, Joan de Borja and Enriquez, duke of Gandia. He ordered Miquel de Maganya to build the mastergate of the irrigation ditch, and Pedro Donzell to build the ditch, after overcoming the opposition of the municipal council of Sueca.
\end{abstract}

Keywords. Irrigation channel, hydraulic engineers, barony of Corbera, Joan de Borja i Enríquez.

\section{Introducció}

La present comunicació vol centrar-se en la gènesi d'un sistema de reg, el de la séquia Major de l'extingida Vila i Honor de Corbera (també coneguda popularment com la séquia dels Quatre Pobles) ${ }^{1}$, la qual conforma un sistema de reg que històricament ha irrigat la major part dels termes municipals de les actuals poblacions de Riola, Fortaleny i Corbera, i unes poques hectàrees del de Polinyà ${ }^{2}$. No és la primera vegada que ens acostem al passat

\footnotetext{
${ }^{1}$ Pense que és obligat fer un breu esment sobre el nom de la séquia. En l'actualitat, és coneguda amb el nom de "séquia dels Quatre Pobles", en clara al·lusió a les localitats que reguen d'aquesta. Però el seu nom oficial, del qual no sempre es fa ús, és el de sèquia Major de l'extingida Vila i Honor de Corbera. Aquest topònim és interessant per dos motius; el primer pel nom en si de "Major", la qual cosa vol posar èmfasi en la jerarquització de l'espai irrigat; i en segon terme, perquè fa esment a la desaparició, "extingida" dirà, de l'antic espai feudal "vila i honor de Corbera". Aquest és el títol que el rei Alfons el Magnànim li atorgà, el 1418, en recuperar-la per a la Corona, i ha estat el nom de la senyoria quan ha format part del Reial Patrimoni: 14181465 i 1580-1837, any aquest darrer en el qual es dissol aquesta entitat per formar cada poble que la integrava ajuntament propi. I si la senyoria o baronia pren el nom de Corbera és pel castell, ja que no era aquesta localitat la més important, sinó que era Riola, el lloc més poblat, i el territori on s'obri la séquia Major i on està el canó, és a dir, la porta que obri i tanca l'entrada de l'aigua a la séquia; per això, al final del segle XVI rebia el nom de la séquia de Riola.

${ }^{2}$ En 1850 les aigües de la séquia Major de l'Extingida Vila i Honor de Corbera irrigaven 7.291 fanecades. D'aquestes, 4.000 corresponien a Corbera, 1.800 a Fortaleny, 1.400 a Riola i 91 a Polinyà. Vide Arxiu Municipal de Corbera (AMC): Fons Sèquia Major. "Espediente de las deliberaciones y demás atribuciones pertenecientes a la Junta de Aguas de esta estingida Villa y Honor de Corbera en el corriente año 1850"; E$1 / 2$, f. 8 .
} 
d'aquest sistema hídric, ja que en altres ocasions ja ens hem ocupat del regadiu d'aquest sistema de reg durant l'antic règim (Vercher, 1992, 2000, 2005, 2006).

En 1955 la Junta de Govern de la Séquia Major estava interessada a conèixer els origens de la séquia, qui fou el que instigà la seua creació i quan es féu, i per obtindre respostes s'adreçaren a l'Arxiu de la Corona d'Aragó. No era la primera vegada que passava. Cent anys abans, en 1853, la Junta d'Aigües de Corbera acordà nomenar una persona que cercara documents sobre els seus drets de reg en l'esmentat arxiu ${ }^{3}$. Però, a diferència del segle XIX, en què la iniciativa no fructificà per qüestions econòmiques, ara sembla que obtingueren dos curtes respostes. Que l'artífex del principal regadiu en el marge dret del Xúquer fou "Ramoneta d'Encarroç", i que aquell datava de "1410". Cap de les respostes era correcta, però serviren per construir una identitat falsa, assentada en l'oralitat sobre la història de la séquia de l'extingida séquia Major de la Vila i Honor de Corbera.

El nostre propòsit amb aquesta comunicació no és sols repristinar els orígens de l'esmentada séquia, sinó esbrinar algunes qüestions com ara: com?, quan?, per què?, qui fou el que la manà bastir? Però, no ja per respondre a preguntes de naturalesa $\mathrm{i}$ àmbit purament local, que per a poc serveixen, sinó per posar en connexió el naixement d'un sistema hidràulic amb el seu context en la comarca, $i$ adonar-nos que amb aquest nou reg s'assentaren els fonaments per a un profund canvi en la Ribera Baixa del Xúquer, l'expansió del cultiu arrosser, així com la transformació i roturació d'àrees fins eixe moment marginals. I això produí un nou paisatge "cultural" en la regió ara fa 500 anys.

Les fonts documentals emprades en aquesta investigació, encara que no totes, procedeixen de l'Archivo Histórico Nacional, fons Noblesa, subfons Osuna, que es conserven actualment a l'Hospital Tavera, a Toledo.

\section{Una veritable revolució hidràulica}

Ja fa uns anys Antoni Furió i Luis Pablo Martínez (1994), en una interessantíssima comunicació a un congrés d'Arqueologia, encunyaren el terme revolució hidràulica de la Ribera del Xúquer, referint-se a allò que passava a la comarca durant els segles XV i XVI. Certament, el terme que empraren és força afortunat per descriure els profunds canvis que s'articularen en l'esmentat territori durant aquestes centúries. Nosaltres, per la nostra part, volem contribuir a aprofundir en el coneixement d'aquests canvis parant l'atenció en el que s'esdevenia a la Ribera Baixa del Xúquer en general, i en particular en el seu marge dret durant els primers decennis del segle XVI, que és el moment en què aquest indret se suma als intensos canvis que s'operaren en matèria de reg.

Abans, però, esmentarem com i per què es produí la revolució hidràulica. La Corona, el 15 de juliol de 1415, concedia a la vila de Cullera el privilegi de poder traure aigua del riu Xúquer per a regar les seues terres sempre amb la condició de deixar aigua suficient per a permetre la navegació en el riu. Sols dos mesos abans, el 26 de maig, autoritzava per primera vegada el tancament complet dels assuts sense necessitat de deixar portells (Furió i Martínez, 2000). Menys conegut que el privilegi anterior és la facultat donada per Alfons el Magnànim, el 1420, en què afavoreix els "homines Villarum Honoris de Corbera, Cullarie et locorum de Çueca, de Albalat, e de Segayren et aliorum locorum existenciarum in lictore rivi Xuquaris a dicto rivo cupiunt extrahere aquam, unde possint suas rigare possessiones

\footnotetext{
${ }^{3}$ Arxiu de la Diputació de València: Aigües. Expedients generals; 3.1., caixa 143, exp. 3.239.
} 
sive hereditates" (Vercher, 2000) ${ }^{4}$. Molts anys després, abans de 1452, el lloctinent del regne, Joan de Navarra, havia autoritzat Cullera a traure una séquia a l'altra banda del riu, és a dir, en el marge dret. El 14 d'abril de 1488 el rei Ferran el Catòlic facultava els particulars de Cullera per a construir un assut i poder traure aigua del riu. En aquest privilegi s'esmentava que el nou canal de reg havia de transcórrer per terres de la baronia de Corbera. En 1509 Cullera continuava traient la seua séquia Major del marge dret, la qual passava pel terme de Corbera; les tensions amb la baronia de Corbera eren remarcables i necessitaren l'empara i vigilància dels oficials reials mentre construïen el seu col·lector, a causa del fonamentat perill de sofrir algun atemptat per part dels de Corbera (Giner, 1992).

Per la seua banda, el mestre de l'Ordre de Santa Maria de Montesa, senyor de la comanda de Sueca, havia obtingut del rei Alfons el Magnànim la facultat de poder prendre aigua per a regar tot el terme d'aquesta (Furió i Martínez, 1994). Aquests privilegis serviren per bastir assuts amb els quals elevar el nivell fluvial i fer decantar l'aigua cap a la séquia que distribuiria l'aigua del riu per a regar el terme; així, s'obria la porta a la construcció de les grans séquies sobre el Xúquer. Els nous col·lectors hídrics que prendrien l'aigua del riu transformarien l'antiga ordenació islàmica del reg en què predominava la petita hidràulica andalusí, com també la hidràulica feta pels colonitzadors cristians a partir de meitat del segle XIII. Això suposava igualment eliminar les barreres al bastiment de grans infrastructures, com ara els assuts que comportaven els drets de navegació, ja que des d'època de Jaume I, en el segle XIII, s'havia de deixar obert un portell en els assuts sobre el riu d'uns 25 pams (uns 5,5 metres), el qual feia inviables la construcció dels grans col·lectors en el seu darrer tram en no poder construir preses per embassar l'aigua.

Durant la segona meitat del segle XV, en 1484, el lloctinent del batlle general, Berenguer Mercader, en nom del Catòlic, donava la llicència i facultat a la universitat de Sueca per obrir una séquia de tanta amplària $i$ fondària com volguera. Prompte Sueca començà a construir el seu assut, aprofitant l'antiga resclosa existent en el molí del Figueral per a traure la seua séquia Major, la qual s'acabaria de bastir el 1506.

El 1508 la duquesa de Gandia, Maria Enríquez, senyora de la baronia de Corbera, manifestarà "ab un privilegi real" la seua voluntat de "traure una cèquia del riu de Xúquer per a la baronia de Corbera", la qual cosa seria ràpidament contestada per la negativa de la vila d'Alzira. No obstant, una comissió del governador reunirà les dues parts enfrontades: el cavaller d'Alzira mossèn Bertomeu Serra, propietari d'un molí, "que està dins los murs de la vila de Algezira", i representants de la duquessa de Gandia, en el lloc on es pretenia fer un assut per a la nova séquia, junt al Xúquer al seu pas per l'alqueria de Moncada, pròpia del monestir de Santa Maria de la Murta però enclavat en el terme de la baronia de Corbera, si bé ja en el seu límit confrontant amb Alzira. En aquell acte d'ajust i medició de l'anivellament del riu on es podia fer un nou assut en el Xúquer i prendre l'aigua per a irrigar el marge dret, assistiren com a tècnics mestres livelladors fra Antoni Vidal, monjo de la Murta, i el mestre Melcior Ferrer, de Gandia 5 .

Finalment, aquesta obra s'executà, ja que d'uns anys més tard, el 17 d'octubre de 1519, és l'acord dels monjos de la Murta d'encomanar a un benfactor seu, el cavaller Santamaria, que negocie amb el duc de Gandia la donació, a perpetuitat, del bovalar i del terç delme de

\footnotetext{
${ }^{4}$ ARV: Real. Titols i enagenacions del reial patrimoni; 611, f. 196v.

${ }^{5}$ Archivo Histórico Nacional (d'ara endavant AHN): Noblesa. Osuna. "Sobre pretensión que tiene la duquesa de Gandia de sacar una acequia del rio de Júcar para obs de la universidad de Corbera. Año 1505 (sic)”; lligall $725-2 / 15$.
} 
l'alqueria de Moncada en compensació del pagament del dany causat en la seua heretat per la séquia que obrí el duc ${ }^{6}$.

Un dels impulsors de d'aquesta "revolució hidràulica" és, sens dubte, un dels nobles més importants del regne de València. Aquest no és altre que el nét del Papa Alexandre VI, el tercer duc de Gandia, Joan de Borja i Enríquez (1493-1543), del qual sabem, que, al menys, engegà dos projectes de séquies en la baronia de Corbera: la séquia de Montcada i la séquia Major de Corbera, i el 1518 no dubtarà a enfrontar-se amb el marqués de Zenete, senyor de les baronies d'Alberic, Alcosser i Alàsquer, en defensa dels seus drets i dels dels seus vassalls d'Albalat de la Ribera, defensant les legítimes aspiracions d'aquests al repartiment de l'aigua de la séquia Reial d'Alzira?

\section{Els antecedents per a conseguir una séquia mare}

Si bé la consecució de construir, o millor dit, excavar una séquia que vertebrara amplament el territori de la baronia de Corbera s'aconseguí a començaments del segle XVI, és just esmentar els intents o inciatives que es produïren amb anterioritat. El primer d'ells amb èxit i el segon malaguanyat. Açò demostra que ha estat una constant "històrica" la voluntat per part de les comunitats camperoles del territori de bastir uns col·lectors hídrics amb què irrigar les terres.

Les més antigues referències que ens parlen de l'existència de séquies en la senyoria de Corbera fetes pels colonitzadors cristians després de la conquesta es remunten a l'últim decenni del segle XIII. Així, en el territori de Riola s'esmenta una "Cequia Nova" al costat del riu Xúquer en 1290. A les terres de l'alqueria de Sinyent, en 1294, es fa menció d'una "Cequia Maiori". Tots dos topònims són força reveladors i eloqüents, ja que ens parlen d'una jerarquització de l'espai irrigat en dos punts del terme de la baronia un tant distants, alhora que fan referència a altres séquies o col·lectors preexistents $\mathrm{i}$ a l'existència d'una anterior xarxa de reg.

Efectivament, a començaments del segle XIV, durant el regnat de Jaume II el Just (12911327), el regne de València coneix una singular època d'expansió econòmica. Aquesta tindrà com a conseqüència obres de dessecació de marjals al llarg de tot el litoral valencià (Torró, 2009, 2010, 2012a, 2012b), que particularment en la comarca de la Ribera Baixa del Xúquer se centraren en la dessecació de la marjal de Corbera-Cullera, en la construcció de canals d'evaquació o drenatge d'aigua, en el repartiment de lots de terra als pobladors i treballadors de l'empresa règia, i en la construcció de séquies de reg (Furió, 1986).

L'altre episodi d'intentar articular una zona irrigada tingué lloc a mitjans del segle XV. En 10 d'abril de 1457, les autoritats municipals de la Vila i Honor de Corbera, açò és, el justícia, els 4 jurats i els 90 veïns de la vila, entre ells els consellers i prohoms, ajustats en l'església parroquial de Riola, unànimement nomenaren el donzell Simó Pere Marrades, habitant a Polinyà, síndic i procurador seu per a en nom de la universitat carregar-se un censal de fins a 15.000 sous amb el qual començar a bastir una nova séquia que prenguera

\footnotetext{
${ }^{6}$ Biblioteca de l'Ateneu Mercantil de València (BAMV): Fons Almarge. Llibre d'actes capitulars del Monestir de la Murta dels anys 1506-1552; ff. 38r-v.

${ }^{7}$ AHN: Nobleza. Osuna; lligall 696, doc. núm. 4. El procés se substancià en la cort de la Batllia General de València.

${ }^{8}$ Vercher Lletí, S. (2009): La senyoria de Corbera en l'època de Jaume I (1238-1276), Corbera, Ajuntament de Corbera, pp. 74-75.
} 
aigua del riu Xúquer i augmentar el terreny irrigat ${ }^{9}$. La raó que movia els camperols a reunir-se en assemblea per a tractar sobre la viabilitat de realitzar unes noves obres d'infraestructura per al reg de les seues terres derivava, com es reconeixia en el preàmbul del document, de l'intent de posar fre als problemes esdevinguts arran d'una sèrie de collites estèrils per manca de pluges. Pocs dies després de la junta esmentada es comunicava a les autoritats de la limítrofa vila d'Alzira la seua voluntat d'obrir un canal de reg: "com la universitat de la vila de Corbera volgués traure del riu de Xúquer una céquia per a obs de regar les possessions del terme de Corbera, la qual entenen pendre en dret de la dita vila de Algezira, si'ls serà fet contrast $\mathrm{o}$ no, $\mathrm{o}$ si serà perjudicial a la dita vila de Algezira o no" $\left(G u a l\right.$ Camarena, 1979) ${ }^{10}$. L'endemà, el 22 d'abril de 1457, es reunia el consell municipal d'Alzira i acordà denegar la petició de prendre aigua en el seu terme, i amenaçava amb enviar un missatger al batlle general del regne per a donar-li a conèixer els perjudicis que d'això es podia derivar, així com posar l'afer en estudi d'advocats de la municipalitat per a, atés el cas, engegar un procés judicial ${ }^{11}$. En aquesta època, ambdues viles, Alzira i la vila i honor de Corbera formaven part del Reial Patrimoni, i per tant les dues entitats municipals, en última instància, estaven sotmeses al magistrat que defensava els interessos de la Corona en el regne de València, el batlle general, per això el presumible perjudici a Alzira. Tenint en compte que les noves terres irrigables també eren de jurisdicció reial, l'operació suposadament perjudicial per a Alzira no tenia perquè ser-ho per a la Corona. Alzira aquest mateix any, 1457, estava immersa en un plet contra Sueca a causa de les séquies de Campanar, una alqueria del terme municipal alzirenc pròxima a Sueca ${ }^{12}$. A més, havia rebut l'any anterior una carta reial d'Alfons el Magnànim, de Nàpols estant, el 14 d'agost de 1456, per tal que facilitaren l'ajuda necessària a Eximèn Pérez de Corella, comte de Cocentaina i portantveus de governador del regne de València, en la séquia que s'estava construint per traure aigua del riu dels Ulls, un afluent del Xúquer, i bonificar i irrigar els seus llocs d'Albalat de la Ribera, Pardines i Segairent, tots ells en terme general d'Alzira. ${ }^{13}$

Avortada aquesta iniciativa d'expandir la zona regada no tornarà a plantejar-se novament una nova proposta similar fins a començaments del segle XVI, però ara ja en un altre context, ja que la baronia de Corbera no formarà part del Reial Patrimoni, sinó d'una important casa nobiliària, la dels Borja.

\section{La concòrdia entre el duc i vassalls de la baronia de Corbera}

L'1 de maig de l'any 1510 el justícia de la senyoria de Corbera, Bartomeu Pineda, i els jurats Salvador Sobirats, Gaspar Martorell, Miquel Esteve i Antoni Renart, juntament amb el consell municipal de la vila, honor i baronia de Corbera, reunits en assemblea a l'interior de

\footnotetext{
${ }^{9}$ AHN: Nobleza. Osuna; lligall 727/26 (carpeta 98, núm. 3).

10 Vide Arxiu Municipal d'Alzira (d'ara endavant AMA): Llibre d'actes dels jurats i consell de l'any 1456-1457; 03/47, ff. 292r-296r.

11 "Sobre lo fet de la céquia que volen traure los de Corbera, que en alguna manera no permeten ni consenten que aquella sia treta entorn dels termens de la dita vila, ans los sia fet contrast o manament que aquella no facen, e si necessàri serà que sia tramés missatger o missatgers al màgnifich batle general del regne de València, consultant-lo dels grans perjuhis que per causa de la dita céquia serien fets a la dita vila e singulars de aquella". Vide. Gual Camarena (1979).

12 Gual Camarena (1979, pp. 148-149). Vide. AMA: Llibre d'actes dels jurats i consell de l'any 1457-1458; 03/48, ff. 6r-7r.

${ }^{13}$ Gual Camarena (1979, pp. p. 146) Vide. AMA: Llibre d'actes dels jurats i consell de l'any 1456-1457; 03/47, ff. $169 \mathrm{v}-170 \mathrm{r}$.
} 
l'església de Santa Maria de Riola, decidiren construir una nova séquia per intentar posar remei als seus greus problemes de producció, els quals derivaven de l'adversa climatologia: "propter sterilitatem temporis indiget frumentis et aliis bladis et granis ad opus suportandi vitam humanam et alendi omnis vicinos et habitatores dicte ville". En aquella important reunió s'elegí Antoni Martorell, un destacat llaurador de Riola, com a síndic per a contractar un crèdit, un censal de fins a 21.000 sous. En el pergamí que recollia l'acta de l'elecció també s'assenyalava que amb els diners s'especificava també on es volia construir la séquia amb què esperaven acabar amb els seus mals: "qua propter fuit decretum et ordinatum extrahere quandam cequiam a flumine Xuquaris intus terminum villa Algezire et prope terminum dicte baronie ad et per opus rigandi terras et possessiones termini dicte ville et baronie Corbaria". ${ }^{14}$

L'acte anterior, lluny del que poguérem pensar, no era un acte autònom decidit pel consell municipal de la baronia de Corbera, era conseqüència d'un acte jurídic adoptat uns mesos abans i de cabdal trascendència, una concòrdia signada el 26 de febrer del dit any, 1510, en què els protagonistes no sols eren els vassalls de la baronia, cristians i mudèjars, sinó en primer lloc i com a autor intel·lectual del document el senyor de la baronia.

Efectivament, Maria Enríquez i Luna (1474-1539), vídua de Joan de Borja i Cattanei (14741497), segon duc de Gandia, tudora i curadora del fill d'ambdós, el jove Joan de Borja (1493-1543), senyor de la baronia de Corbera, fou la instigadora d'un pacte o concòrdia amb les universitats de la senyoria, és a dir, amb tots els seus vassalls. A través d'11 capítols s'acorden una sèrie de qüestions relatives a l'obertura d'un canal de reg, la seua administració, despeses de gestió i manteniment, i planificació de nous equipaments productius sobre la séquia com ara molins arrossers o fariners. La duquessa es comprometia (capítol 1) a traure amb el seu propi càrrec una séquia del riu Xúquer per a regar les terres de la dita baronia. En contrapartida, els veïns i habitadors de la baronia havien de donar 10 jornals per cada casa. Això significava 2.170 jornals, ja que el famós cens del regne de València de 1510 manat fer per les Corts de Montsó estableix per a Corbera i la seua baronia 217 cases (Valldecabres, 2002). Igualment els veïns beneficiats amb el reg restaven obligats a pagar anualment un diner i mealla (mig diner) per cada fanecada de terra (831 metres quadrats o 0,0831 ha).

També estava concordat que el duc "reste senyor y perpetualment de la dita cèquia, en axí que aquell sia tengut e obligat conservar aquella a ses despesses, ço és, les despesses que seran necessàries per a conservatió del açut de la dita cèquia y del canó de aquella e dels trenchs que's seguiran en la dita cèquia e de fer los ponts en dita cèquia e conservar aquells, açò emperò declarat que los vehins de la dita baronia e terratinents que regaran de dita cèquia sien tenguts de scurar la dita cèquia com serà menester...”.

El senyor s'assegurava que els seus vassalls moldrien els seus grans, tant de cereals com d'arrossos en el molí que construiria sobre la séquia, els quals "no puixen anar a molre en altre loch a pena de perdre lo blat que portaran a molre a altres qualsevol molí fora de aquells dits molins o preu de aquell. En axí que los dits molins sien entessos ésser agarbellats per als vehins e habitadors de la dita baronia puix emperò los dits molins proveixquen la dita baronia e serveixquen bé e lealment la dita baronia”.

\footnotetext{
${ }^{14}$ Vercher Lletí (2000, pp. 149-150). Arxiu del Regne de València (d'ara endavant ARV): Vària. Pergamins; núm. 45.
} 
Els Borja, en el capítol 5è de la concòrdia, també deixaren tancat que el manteniment de la neteja de la séquia havia d'anar a càrrec dels seus vassalls: "emperò declarat que los vehins de la dita baronia e terratinents que regaran de la dita cèquia sien tenguts de scurar la dita cèquia com serà menester al qual scurar de la dita cèquia lo il lustre duch, ni sucessors de aquell, no sien tenguts, ni obligats y que aquell puixa compel-lir los vehins e habitadors de la dita baronia e terratinents al scurar de la dita cèquia o a despesses de aquelles fer scurar aquelles".

En el capítol 7è s'aprovava que el duc es reservava el dret d'elegir anualment el sequier "per a regir la aygua de la dita cèquia e tenir en guarda a aquella"; a més, el salari d'aquest havia d'anar a càrrec del senyor. En el següent ítem, el 8è, el senyor es reservava el dret de "fer les ordinations puixa que seran necessàries per a la guarda e conservació de la dita cèquia e repartiment de la dita aygua". Igualment, el pacte li conferia la facultat d'imposar penes a aquells que infringiran les normes per ell dictades, així com també gaudirà de la facultat de fer execucions ${ }^{15}$.

El fet que per iniciativa del senyor de la baronia de Corbera, el duc de Gandia, coneguem l'obertura de dues séquies, pràcticament a un mateix temps, podria suggerir l'existència d'una "política hidràulica" planificada en les seues baronies. Dissortadament no ho podem comfirmar, ja que no ens consta cap actuació similar a Albalat de la Ribera, Torís, ni en la senyoria de Llombai, totes tres baronies també situades en la Ribera del Xúquer i propietat en aquest temps del mateix senyor Joan de Borja, tercer duc de Gandia. Però no deixa de ser significatiu que el duc apostara pels projectes de bastir les dues séquies en la baronia de Corbera, això si més no es desprén d'una acta del consell municipal d'Alzira, de 16 de juny de 1513, en la qual s'esmenta que Joan de Borja tenia tècnics nivelladors a Alzira: “... com en la present vila hi havia tres mestres d'aigua tramés per lo il·lustre duch de Gandia y alguns de casa sua segons han entés per veure lo scurament del riu y molts per lo regolf se diu lo açuts de la sequia que ha tret se pren per part de los dits senyors de molins y per la vila demanaven de consell si sabien les causes de la venguda de aquells e demanaven als dits mestres de les causes de la venguda si han lo ple de aquell sobre dites coses e dan que pren la vila lo dit açut del dit il·lustre duch als dits moliners i vila" ${ }^{\prime 16}$.

\section{Les primeres dificultats: els enfrontaments amb Sueca}

Comentava encertadament Thomas F. Glick que els enfrontaments i conflictes per qüestions d'aigües derivaven en definitiva de la posició dels regants, els d'aigües avall o jussans amb els d'aigües amunt o sobirans. I a açò hem d'afegir que també s'esdevenen conflictes derivats de l'aprofitament d'infraestructures comunes.

Tot just després que les universitats de Riola i Fortaleny elegiren síndic per a carregar-se un censal amb el qual fer front a les quantioses despeses que anava a suposar l'obertura del nou canal de reg i després d'haver signat el contracte, el 8 de gener de 1516, amb el mestre pedrapiquer de València, Miquel de Maganya, de les obres del canó per prendre l'aigua per irrigar en el marge dret del Xúquer aprofitant l'assut del molí del Figueral que era la infraestructura que garantia el reg de la séquia Major de Sueca, degueren començar les

\footnotetext{
15 AHN: Nobleza. Osuna; caixa 726, document 44.

${ }^{16}$ AMA: Llibre d'actes dels jurats i consell de l'any 1513-1514; 03/102, f. 17r-v.
} 
obres en la baronia de Corbera. A finals d'eixe mateix mes, el 25 de gener, la vila de Sueca interposava un plet de ferma de dret ${ }^{17}$ davant la cort del Governador de València ${ }^{18}$.

El clam o denúncia del consell municipal de Sueca contra l'obertura de la nova séquia per part de la baronia de Corbera, sembla que tenia com a finalitat forçar una negociació a fi d'obtenir Sueca certs avantatges a l'hora de mantenir en bon estat de conservació el seu assut, columna vertebral del seu nou regadiu. El conflicte sempre comporta una "condició de negociació" (Glick, 2005). Els advocats de Sueca exposaven davant la cort del governador que ells estaven en pacífica possessió de prendre l'aigua del riu a través de l'assut del molí del Figueral i que l'obertura de la nova séquia en el marge dret anava a causar dany i perjudici en el marge esquerre, açò és, en terme de Sueca, sense donar més arguments referits, tant a la possessió, com als possibles perjudicis dels quals en seria objecte. I també assenyalaven que el nou canal de la baronia de Corbera causaria "distrució e depopulació de aquella [Sueca]" i que els seus molins —en tenia dos, un fariner i l'altre arrosser-, no podrien moldre els grans.

Efectivament, com assenyala T. F. Glick (2005, pp. 357-358) — tot seguint D. L. Smail (2003) — , els regants empraven els tribunals per a negociar el seu estatus davant altres grups d'interessos i competidors seus. Sueca pretenia marcar territori i intentar forçar una negociació. De fet, en els plets que afectaven elements arquitectònics, com és el nostre cas a causa de l'assut, el testimoni dels experts era fonamental, així com la inspecció visual o ocular in situ dels oficials del tribunal o experts ("livelladors") nomenats pel governador, $i$ ambdues operacions tècniques varen ser conscientment boicotejades per Sueca malgrat que "ha request la dita universitat (Riola i Fortaleny) que's concordassen de persones spertes per a que mirassen si per la dita nova séquia ... se seguis dan algú a la dita séquia e molins de Sueca" ${ }^{19}$, com assenyalava el síndic de la baronia de Corbera, el notari Joan Garcia.

Pel que fa a les argumentacions que esgrimia el síndic dels pobles de Riola, Fortaleny i Beniatzit a part de denunciar que la part contrària, açò és, "Sueca sabent la veritat del dit fet, ço és, que dan(y) algú no li seguys diferix e ha diferit la dita concòrdia e açò fa per que los dits propossants no's haprofiten de la dita aygua, los quals tenen gran necessitat de aquella com haja molt temps que no ha plogut hi es cert que obrint la dita séquia porien remegar llur necessitat per regar los seus blats e preparar los plante(r)s dels arrossos", ${ }^{20}$ aquest síndic perseguia que la cort decretés que ambdues parts litigants es posassen d'acord a l'hora de nomenar els experts que inspeccionaren sobre el terreny l'assut "de Sueca" i les obres del nou canal de $\operatorname{reg}^{21}$.

L'estratègia de defensa dels seus interessos que portaren a terme els síndics de Sueca es revetlà eficaç, ja que, malgrat les denúncies de la part contrària de no presentar-se en l'assut, ni de nomenar tècnics experts, aconseguiren a partir del 19 d'abril i fins al 14 de maig del dit any, 1516, de manera conjunta entre ambdues parts contrincants, sol-licitar i aconseguir prorrogar les sessions del plet, el qual restà al remat inconclús, i, sense sentència.

\footnotetext{
${ }^{17}$ La ferma de dret és una mena de procés en el qual la part pledejant invocava com a garantia de l'acatament $\mathrm{i}$ compliment de la resolució que caigués en judici.

${ }^{18}$ AHN: Nobleza. Osuna; lligall núm. 725/2-24.

${ }^{19}$ AHN: Nobleza. Osuna, lligall núm. 725/2-24, f. 15v.

${ }^{20}$ Idem.

21 “... requir lo dit Johan Garcia, en los dits noms, que per Vostra Senyoria sia provehit e manat a la dita universitat de la dita vila de Sueca que dins tres dies se haja concordat ab lo dit propossant de persones spertes de mirar si per la dita séquia nova se seguys lo pretés dan a la dita vila de Sueca e a la séquia e molins de aquella”. AHN: Nobleza. Osuna, lligall núm. 725/2-24, f. 15v.
} 
És evident que la pròrroga que durant quasi un mes impulsaren les parts litigants era un temps mort, judicialment parlant, mentre negociaven una solució al conflicte al marge del que poguera imposar el president del tribunal, el governador de València.

Dissortadament, no coneixem l'acord final a què arribaren els gestors de la séquia Major de Sueca i els representants dels camperols de Riola, Fortaleny i Beniatzit que aspiraven a obrir la seua séquia. El dit document no s'ha conservat entre els dipòsits arxivístics municipals de Sueca, de la baronia de Corbera, a Riola, ni tampoc en l'arxiu ducal de Gandia, ni entre els protocols dels notaris que intervingueren en l'afer. Creiem que la posició del consell municipal de Sueca d'enfrontar-se a la vila i baronia de Corbera en negar-se la primera a poder traure una séquia que beneficiés la segona, s'explica per l'interés a forçar una negociació al marge del procés judicial i començar aquesta amb una posició de força.

Si la construcció de l'assut del qual prenia aigua la séquia Major de Sueca s'havia pagat amb diners del consell municipal de Sueca, és factible creure que ara aquesta volguera rescabalarse i que els nous beneficiaris de l'estrenada infraestructura contribuïren d'alguna forma al manteniment d'aquesta. No sabem si fou així, ja que acabem de dir que no hem trobat els documents que ho testimoniaren. No obstant, hi ha alguns indicis que apunten al fet que això poguera haver-se produit. Sueca, en ocasions, se servia dels forns de calç i de les pedreres de Corbera per a obres com ara l'assut i el canó. Tenim altres dades de que al llarg del segle XVI ens parlen que mudèjars de Corbera eren contractats per Sueca per a submergir-se en l'aigua del riu Xúquer per fer treballs de manteniment del canó i de l'assut. Així, destaca un personatge com ara Roger, un morisc de Corbera, que entre 1541 i 1560 fou requerit per "cabuçar-se" fins a en 53 ocasions (Mira, 1995). I ja de finals de l'any 1600 hi ha una notícia que ens indica que el duc de Gandia (que ja no era senyor de la baronia de Corbera des de 1580) contribuia al manteniment de l'assut (que compartien Sueca i Corbera) pel seu molí fariner ${ }^{22}$.

\section{Els contractes per a construcció del canó i de la séquia}

Els elements més importants, o si es vol, imprescindibles per fer viable un sistema de reg que prenga l'aigua del riu són tres: un assut que retinga l'aigua i l'eleve; el nivell de l'aigua dins del riu, i un canó o construcció que transvasse, regule, òbriga i tanque el pas de l'aigua des del riu a la séquia mare i la seua xarxa de filloles, braçals o séquies de distribució per l'àrea del sistema.

Afortunadament, documentem dos dels tres elements. No així el primer, açò és, l'assut del molí fariner del Figueral. Aquesta presa és la capçalera del sistema hidràulic de la séquia Major de Sueca. Ja hem dit amb anterioritat que el 2 d'abril de 1484, Berenguer Mercader, lloctinent del batlle general, facultava en nom del sobirà la universitat de Sueca a poder treure aigua per a fer una nova séquia, la qual fou conclosa el 1506 (Furió i Martínez, 2006). Per tant, entre els darrers anys del segle XV i començaments de la següent centúria s'operà la remodelació i transformació de l'antiga resclosa que embassava aigua per moure el molí fariner del Figueral, un molí d'origen islàmic. L'assut, com sabem, és el primer element de la infraestructura d'un sistema d'irrigació fluvial (Mateu, 1989).

\footnotetext{
22 “De l'arrendament del molí arrocer de Riola no se'n fa càrrech en lo present any -1600- per no haver-se lliurat ans bé fonch subastat y jamés se trobà dita alguna per estar rompuda la açut de Riola la qual lo duch solia conservar per rahó del molí fariner que està contiguo a lo dit molí arrocer”. Vide. ARV: Mestre Racional. Comptes de l'administració de la batllia de Corbera de l'any 1600; 2.818.
} 
El 8 de gener de 1516 el justícia de la baronia de Corbera, Pere Martorell, un jurat de Riola i un altre de Fortaleny, juntament amb altres 36 veïns de Riola, 23 de Fortaleny i 3 de Beniatzit elegiren i nomenaren síndic Antoni Martorell, de Riola, per a contractar un crèdit (censal) en nom de tots ells de fins a 9.000 sous a fi d'esmerçar-los en la construcció d'una séquia que prenia aigua del Xúquer, prop del molí del Figueral, aquest darrer en terme de Sueca, per a regar les seues terres ${ }^{23}$.

El referit dia també se signaven a Riola, davant del notari del lloc Miquel Tafoya, els capítols del nou canó que s'havia de construir sobre l'assut del Figueral ${ }^{24}$, una obra que s'avaluà en 5.700 sous. Els signants del contracte eren per part dels nous regants, el síndic Antoni Martorell, i per l'altra el pedrapiquer de València, Miquel de Maganya. Però, qui era aquest tècnic? Aquest era un picapedrer, oriund de la localitat de Maganya, en el regne de Castella, que es formà professionalment a València en la colla a les ordres de Pere Compte en la Seu de la capital, la qual cosa es documenta entre 1494 i $1525^{25}$. Maganya en la seua vida professional participà en diverses obres de marcat caràcter hidràulic: la reconstrucció del pont dels Serrans de València el 1518; la reconstrucció d'un assut sobre el riu Millars en terme de Castelló de la Plana; el 1519, l'assut de Baix, sobre el riu Vernissa, a Real de Gandia entre 1520-23, i el canó de la séquia de Corbera, el 1516, la primera de totes elles cronologicament. Però, Miquel de Maganya, juntament amb Joan d'Alacant, en qualitat de "livelladors", foren comissionats pel governador de València per a inspeccionar i fer un informe tècnic sobre l'assut que el duc de Gandia volia traure en el territori de Montcada, de la baronia de Corbera, una séquia tot i l'oposició d'Alzira ${ }^{26}$.

El contracte de la construcció del canó de la séquia Major s'havia d'executar en 12 capítols pel mestre livellador. Després d'assenyalar-se el lloc exacte on s'havia d'ubicar aquesta edificació, açò és, damunt del ja referit assut del molí del Figueral, entre el camp de Jerònim Andrés i el camp de Bernat Torremocha, i el riu Xúquer, es dóna pas als capítols 2 a 7 que enregistren de manera detallada i amb mesures com i de quina manera s'ha de bastir.

Acte seguit els capítols recullen altres qüestions relatives a altres afers no tècnics però no per això de menor importància, com ara —el capítol 8è- la necessitat d'establir una inspecció per dos tècnics (mestres livelladors), cada un proposat per cada una de les dues parts implicades, la part contractant i la contractada. En el 9è es fa referència al termini d'acabament de l'obra — durant el mes de maig—, així com el compromís de "de donar pas y haviament per lo dit canó a la dita aygua per a vint dies del mes de abril primer vinent", sens dubte per assegurar-se l'aigua per plantar els arrossos.

\footnotetext{
${ }^{23}$ AHN: Nobleza. Osuna; lligall 725/2-25. L'acte fou protocol litzat pel notari Miquel Tafoya.

${ }^{24}$ AHN: Nobleza. Osuna; caixa 725, document 44 (olim lligall 725-2/28) "Capítols fets y fermats entre mestre Miquel de Maganya, pedrapiquer, y lo honorable en Anthoni Martorell, en cert nom”.

${ }^{25}$ La nòmina d'obres en què va intervindre Miquel de Maganya és llarga: en l'Arcada Nova de la Seu de València en 1494; en l'obra de la Casa de la Diputació en 1511; en l'Hospital General de València treballarà des del 1513 fins 1517; a la capella del Rosari de l'església del Monestir de Sant Domènec de València, el 1514; en la reconstrucció del pont dels Serrans el 1518, després de la gran riuada de l'any anterior; a la cartoixa de Valldecrist, prop de Sogorb, el 1522, i a l'església parroquial d’Utiel el 1523. Vide Gómez-Ferrer (1998) i Serra Desfilis (2011).

${ }^{26}$ En l'informe de la medició s'esmenta que: "anaren a livellar de davall de un assut de Riola \fins/ a un altre asut que·s diu del molí nou que es de Sueca”. Vide AHN: Nobleza. Osuna; caixa 725, document núm. 46.
} 
L'obra — segons s'establia en el capítol 10è- s'havia de satisfer en tres pagues iguals: la primera durant la setmana després de la signatura del moment del contracte, la segona en el moment en què estiguessen fets els fonaments, i la darrera quan s'acabés el canó. Maganya rebia l'ajut de tindre al seu abast tants forns de calç com necessitara. Si bé els havia de manar fer el síndic, aquests havien de ser pagats pel mestre d'obres. Finalment, els capítols del contracte recullen una darrera clàusula, la 12a, en la qual s'estipula una mena de premi suplementari per al mestre d'obra, com ara una "sort" o camp d'arròs franc de preu i sequiatge per cinc anys. El procurador del senyor en la baronia de Corbera, el cavaller Ricard Martí, actuà de testimoni en el dit contracte.

La construcció, o millor dit, l'excavació de la séquia Major que acabaria irrigant la major part de les terres de la baronia de Corbera, és el resultat d'un contracte entre dues parts. D'una banda, el que encarrega l'obra, el duc de Gandia, Joan de Borja, senyor de la baronia de Corbera; i de l'altra, el que l'ha d'executar, que no és un altre que Pedro Donzell, veí de la ciutat castellana de Logronyo. Unes capitulacions signades el 9 de desembre de 1516, davant el notari Joan Garcia, establien les clàusules que havien de regir el bastiment del nou canal de reg. L'objecte del contracte apareix plenament definit en el preàmbul del document: "sobre la aygua que lo dit Pedro Donzell se offir traure del riu de Chúquer per a regar les terres de la dita baronia y lochs de aquella"27.

Entre les obligacions del duc figuren donar casa franca en la baronia, així com provisió de menjar i beguda a Donzell, la seua muller i fills, i els dos obrers que li ajuden "a fer los artificis necessaris per a traure la dita séquia".

En el segon capítol s'estableix que "Pedro Donzell haja e sia tengut fer tantes trompes i edificis per a traure la dita aygua del dit riu quantes lo dit il·lustre duch volrà y en los lochs que millor fer-se poran y sa senyoria volrà". Per a construir aquests artefactes amb els quals traure l'aigua de la séquia que bastia el duc, havia d'ajudar-lo amb l'aportació de primeres matèries com ara fusta, claus i altres coses necessàries "per a cavar".

Així mateix s'estableix, en el quart capítol, que el duc ha de donar fins a 70 ducats en ajuda de pertrets per a reforçar les parets de la séquia on s'havien d'instal·lar els "artificis" amb què extraure aigua, tot per evitar un dels perills més comuns en les séquies, les solzides.

Igualment, en el capítol 5 s'especifica que Pedro Donzell, tant pels seus treballs de conservació dels artificis per a traure l'aigua, com per les fanecades que gràcies als dits artificis es regaran, es facen pagar als vassalls regants de la dita baronia deu maravedís per fanecada, açò és, sis diners i mealla anualment ${ }^{28}$. Però la percepció del que ha de rebre Donzell per fanecada de cada vassall beneficiari del nou reg es convingué que restava limitada en el temps: "los dits vasalls de la dita baronia regants de la dita aigua no sien tenguts pagar sis diners y mealla per fanecada cascún any, sinó per tant tems quan lo dit en Pedro Donzell los donarà la dita aigua per a regar dites sues terres".

En el capítol 8è s'aplega que el duc ha de donar a l'enginyer que basteix el nou canal uns 30 ducats "durant l'obra dels edificis per a obs de fer fonaments sobre-ls quals les dites obres hajen de fer son lavor". I, en el següent, s'acorda que l'obra que donarà a fer el duc ha de tindre com a contrapartida que els vassalls de la baronia s'obliguen a la conservació de l'assut i al pagament dels sis diners i mealla per fanecada.

\footnotetext{
${ }^{27}$ AHN: Nobleza. Osuna "Acte de concòrdia entre los duch y Pere Donsell per a traure una cèquia en lo riu de Chúquer per a regar les terres de Riola"; lligall 725-2/26, f. 1v. Vercher Lletí (2006)

${ }^{28}$ AHN: Nobleza. Osuna; lligall 725-2/26.
} 
En el 10è capítol, el duc Joan de Borja establia una clàusula per recuperar la gestió i manteniment de la séquia, això sí, indemnitzant l'enginyer que l'havia treta ${ }^{29}$.

En el penúltim capítol s'acordà que tant Pedro Donzell com els seus hereus no puguen vendre ni alienar "lo dret de sis diners y mealla per fanecada" a ningú, si no és el duc de Gandia i els seus successors; i per evitar qualsevol temptació en aquest sentit i lligar el dret de percepció als Borja, s'acorda que "si lo contrari era fet que los dits regants no sien tenguts pagar los dits sis diners y mealla per fanecada". I ja en darrer lloc una clàusula que obliga i lliga totes dues parts "que los presents capítols sien executoris etcètera a pena de mil ducats".

El naixement d'una nova séquia de reg implicarà realitzar prèviament uns estudis sobre el terreny in situ de disseny i planificació, i sobretot de l'orohidrografia de l'espai a irrigar. En altres paraules, la séquia o canal de distribució de cabals d'aigua d'origen fluvial havia de ser concebuda per conduir aigua amb economia de mitjans i d'espai, i/o per això havia de ser dissenyada tot combinant el pendent topogràfic i el cabal que havia de vehicular per ella (velocitat, fricció i radi hidràulic). Aquests estudis que degué realitzar l'enginyer Pedro Donzell, molt probablement es degueren produir abans de la signatura del conveni adés estudiat, ja que es difícil creure que signara el contracte de traure la nova séquia sense haver avaluat abans la feina a fer, i haver traçat un pla o disseny per on havia de discórrer el nou canal de distribució de l'aigua del Xúquer. Encara que no sabem com era el primitiu estudi de Donzell per on havia de discòrrer, el cert és que en bona lògica havia de beneficiar en primer lloc els camperols de Riola i Fortaleny, els més interessats en el projecte.

La direcció de la séquia Major de Corbera pren una direcció cap al centre de la terra marjalenca de la gran marjal de Corbera-Cullera, per a veure's de seguida interrompuda per una séquia més antiga, la séquia del Rei[44], que des de les terres de Polinyà discorre cap a la seua connexió amb el riu Xúquer, al qual torna a abocar aigües sobrants.

\section{Conclusions}

Per explorar i analitzar els efectes de la "revolució hidràulica" que transformà la Ribera (Baixa) del Xúquer, no sols hem de recórrer als dipòsits documentals valencians relacionats amb el territori estudiat, açò és, l'Arxiu del Regne de València, especialment el fons de Governació, i els arxius locals de la comarca com ara l'Arxiu Municipal d'Alzira i el de Sueca, o el de l'extinta Vila i Honor de Corbera, a Riola, que no compta amb documents tan antics de començaments del segle XVI, sinó especialment als dels senyors feudals, en aquest cas l'arxiu de la baronia de Corbera que està integrat en el fons Osuna de l'Arxiu Històric Nacional, a Toledo.

\footnotetext{
29 “Ítem, es concordat que lo dit il·lustre duc volrà rembre lo dit pagament dels dits sis diners y mealla per fanecada y pendre a càrrech de aquell la conservatió dels dits edeficis açò puixa fer tots tems que vulla e bé ... hi sia pagant al dit Pedro Donzell sis-cents ducats e que lo dit en Pedro Donzell sia tengut pagant-li los dits sis-cents ducats de fer venda al dit il·lustre duch del dit dret de sis diners y mealla per fanecada del que regaran e que en lo dit cas los dits vassalls regant de la dita aygua sien tenguts pagar al dit il·lustre duch los dits sis diners y mealla axí com los responien al dit en Pedro Donzell". AHN: Nobleza. Osuna "Acte de concòrdia entre los duch y Pere Donsell per a traure una cèquia en lo riu de Chúquer per a regar les terres de Riola"; lligall 725-2/26, f. 6r-v.
} 
La raó per la qual les comunitats camperoles assentades vora el riu Xúquer es posicionaren tan a favor d'obrir noves séquies per als seus cultius, cal cercar-la no sols en el fet que la Corona havia canviat el seu plantejament tradicional a començaments del segle XV, i havia sacrificat la navegabilitat del riu en benefici dels senyors feudals, i per això lliurà a favor de la vila de Cullera la facultat de fer un assut sobre el riu Xúquer i obrir séquies (després vindria Sueca), això era la conseqüència del canvi de postura, sinó que el vertader motor tal volta cal cercar-lo en la climatologia, desfavorable. Els camperols varen comprendre que les seues economies domèstiques eren massa fràgils per fer fructificar els seues cultius si sols confiaven en la pluja, i apostaren per la recerca de cabals hídrics regulars per a les seues collites. Els, de vegades força reiterats, anys de sequera, feren prendre la consciència que calia reconvertir les terres de secà o marjalenques en terres amb una irrigació planificada.

Però, en aquest procés de transformació agrícola, s’implicà el senyor de la baronia de Corbera abans que ningú, tal volta abans que els mateixos camperols que no eren autonòms per a prendre decisions de tanta trascendència. En definitiva, major producció agrària significava major percepció de rendes, sobretot en un moment en què aquest senyor acabava de fer un gran desemborsament econòmic en comprar la senyoria sols vint anys abans, en 1494, i era el moment de rescabalar-se econòmicament de la gran inversió econòmica satisfeta. A més, en aquest cas el duc de Gandia, Joan de Borja i Enríquez, titular de la senyoria de Corbera, era un personatge suficientment important $\mathrm{i}$ influient com per poder comptar amb els serveis de livelladors, i per això es contractaran dos tècnics en hidràulica: Miguel de Maganya i Pedro Donzell, el primer per fer el canó de la séquia, i el segon per excavar la mateixa séquia.

El naixement de la séquia Major de Corbera, ara fa 500 anys, tingué notables conseqüències en el futur del territori, ja que no sols fou l'element que serví per jerarquitzar l'espai de la Ribera Baixa en el seu marge dret, ja que l'espai pla "marjalenc" es dividí en terres amb dret a regar de la dita séquia $i$ dels seus braçals $i$ les que tenien dret a aigües sobrants o a la compra d'aigua; en aquests casos les terres de la veïna senyoria de Llaurí. També fou el responsable que l'arròs es convertira amb el temps en un dels principals cultius del territori estudiat, $i$ amb el que això significa de radical canvi de paisatge que al cap i a la fi no deixa de ser un reflex o herència cultural de la societat que va fer nàixer el canal de reg que acabem d'estudiar.

\section{Referències}

Furió Diego, Antoni (1986): El camperolat valencià en l'Edat Mitjana. Demografia i economia rural en la Ribera (segles XIII-XVI), València, Facultat de Geografia i Historia. Tesi doctoral, inèdita, vol. III, pp. 777-783.

Furió Diego, A - Martínez Sanmartín, L. P. (1994): “Assuts i molins sobre el Xúquer en la Baixa Edat Mitjana", IV Congrés d'Arqueologia Medieval Española. Actes "Societats en transició", València-Alacant, Generalitat Valenciana-Asociación Española de Arqueologia Medieval, vol. III, pp. 575-586.

Furió Diego, A.-Martínez Sanmartín, L. P. (2000): "De la hidràulica andalusí a la feudal: continuitat i i ruptura. L'Horta del Cent a la Alzira medieval", a Furió Diego, A. - Lairón, A. (eds.), L'espai de l'aigua. Xarxes i sistemes d'irrigació a la Ribera del Xúquer en la perspectiva històrica, València, Universitat de València, pp. 19-73. 
Furió Diego, A.- Martínez Sanmartín, L. P. (2006): "La evolución histórica del regadío en la Ribera Baixa del Xúquer. El margen izquierdo", a Hermosilla Pla, Jorge (dir.), Las Riberas del Xúquer: Paisajes y Patrimonio Valencianos, València, Generalitat Valenciana, pp. 206-218.

Giner Perepérez, F. (1992): "Los riegos del Júcar en Cullera en la época foral”, a Historia y constitución de las Comunidades de Regantes de las Riberas del Júcar (Valencia), Madrid, Ministerio de Agricultura, Pesca y Alimentación-IRYDA, pp. 345-368.

Glick, T.F. (2005): "Regants contra feudals. Observacions sobre uns plets d'aigua a la Ribera del Xúquer", a Afers. Fulls de recerca i pensament, 51: 357.

Gómez-Ferrer, M. (1998): Arquitectura y arquitectos en la Valencia del siglo XVI. El Hospital Generaly sus artifices, Valencia, Albatros, pp. 201-206 .

Gual Camarena, M. (1979): Estudio histórico-geográfico sobre la Acequia Real del Júcar, València, Institució Alfons el Magnànim.

Mateu Bellés, J. (1989): “Assuts i vores fluvials regades al País Valencià medieval”, a Los Paisajes del agua. Libro jubilar dedicado al profesor Antonio López. Gómez, València, Universitat de València, pp. 165-185.

Mira Jódar, Antonio José (1995): "La contratación de la producción artesanal y de la mano de obra mudéjar por el consell de Sueca a principios del siglo XVI", a VI Simposio Internacional de Mudejarismo. Teruel, 16-18 de septiembre de 1993, Terol, Centro de Estudios Mudéjares-Instituto de Estudios Turolenses, pp. 365-372.

Serra Desfilis, A. (2011): "Arquitectura, símbolo y función en la iglesia de Santiago de Villena", a Sancho de Medina y el arcedianato de Villena: política, cultura y fe en torno al Renacimiento levantino, Villena-Alacant, Ajuntament-Universitat d'Alacant, pp. 263-289.

Smail, D.L. (2003): The consumption of justice: emotions, publicity and legal culture in Marseille, 1264 1424, Cornel University Press, Ithaca.

Torró Abad, J. (2009): "Field and canal-building after the conquest: modificacions to the cultivated ecosystem in the kingdom of Valencia, ca. 1250-ca. 1350", a Catlos, Brian A. (ed.), Worlds of History and Economics. Essays in Honour of Andrew M. Watson, València, Publicacions de la Univcersitat de valència, pp. 77-108.

Torró Abad, J. (2010): “Tierras ganadas. Aterrazamiento de pendientes y desecación de marjales en la colonización cristiana del territorio valenciano", a Kirchner, H.: Por una arqueologia agraria. Perspectivas de investigación sobre espacios de cultivo en las sociedades medievales hispánicas (BAR International Series 2062), a Archaeopress (Oxford), pp. 157-172.

Torró Abad, J. (2012a): "One aspect of the christian settlement of the kingdom of Valencia: the drainage and placing under cultivation of coastal wetlands (c. 1270-1320)", a Galetti, Paola (ed.), Paesaggi, comunità, villaggi medievali: atti del convegno internazionale di studio. Bologna, 14-16 gennaio 2010, Spoleto, pp. 225-238.

Torró Abad, J. (2012b): “Colonización cristiana y roturación de áreas palustres en el reino de Valencia. Los marjales de la villa de Morvedre (ca. 1260-1330)", a Torró, J.-Guinot, E. (eds), Hidráulica agraria y sociedad feudal. Prácticas, técnicas, espacios, València, Universitat de València, pp. 147-185.

Valldecabres Rodrigo, R. (2002): El Cens de 1510. Relació de focs valencians ordenada per les Corts de Montsó, València, Publicacions de la Universitat de València, p. 37.

Vercher Lletí, S. (2000): "Sèquies i escorredors a la Ribera Baixa del Xúquer: la Vila i Honor de Corbera (segles XV-XVIII)", a Furió Diego, A. - Lairón, A. (eds.), L’espai de 
l'aigua. Xarxes i sistemes d'irrigació a la Ribera del Xúquer en la perspectiva històrica, València, Universitat de València, pp. 141-161.

Vercher Lletí, S. (2006): "Los fundamentos del regadío histórico tradicional en la Ribera Baixa del Xúquer. El margen derecho. Siglos XIII-XX”, a Hermosilla Pla, Jorge (dir.), Las Riberas del Xúquer: paisajes y patrimonio valencianos. València, Generalitat Valenciana, pp. 219237.

Vercher Lletí, S. (2009): La senyoria de Corbera en l'època de Jaume I (1238-1276), Corbera, Ajuntament de Corbera. 